\title{
Effect of Stevia Leaf (Stevia rebaudiana) Powder Supplementation and Nutrition Counselling on Anthropometric Parameters and Gain in Knowledge of the Subjects
}

\author{
Anita Kochhar, Sahiba Dhindsa and Rajbir Sachdeva \\ Department of Food and Nutrition, Punjab Agricultural University, Ludhiana, Punjab, India \\ E-mail: dranitakochhar@yahoo.com
}

KEYWORDS Anthropometric parameters; knowledge; nutrition counselling; stevia leaf powder; supplementation

\begin{abstract}
Ninety non insulin dependent male diabetic subjects between 40-50 years, free from serious complications were selected from Punjab Agricultural University (PAU) hospital, Ludhiana to study the effect of supplementation of stevia leaf powder and nutrition counselling on anthropometrics parameters and gain in knowledge of non insulin dependent diabetics. The subjects selected were divided into three groups namely group I, group II and group III having thirty subjects each. Group I subjects were only given medicine prescribed by the doctor, group II subjects were given medicine prescribed by the doctor and nutrition counselling and group III subjects were given medicine, nutrition counselling and stevia leaf powder. One gm of stevia leaf powder was incorporated in $500 \mathrm{mg}$ capsules and were given to the subjects daily during breakfast and lunch for three months. Nutrition education was given to the subjects of group II and III for 3 months after fifteen days interval. It was observed that majority of the subjects in all the three groups had craving for sweet foods, liked fried foods. Frequency of consumption of vegetables and fruits by the subjects was increased in Group II and III after nutrition counselling. Physical activity pattern of the subjects of Group II and III was increased after nutrition counselling, significant decrease in weight of the subjects of Group II and III was observed. It was seen that there was a significant increase in knowledge, attitude and practices and hence gain in total knowledge of subjects in Group II and III after three months of the study. While there was a non-significant increase in the knowledge of the subjects of Group I. Hence it can be inferred from the results that supplementation of stevia leaf powder along with nutrition counselling significantly improved the nutritional status of diabetic patients
\end{abstract}

\section{INTRODUCTION}

Globally diabetes affects 246 million people which is about 6 per cent of the total adult population. It is the fourth leading cause of death by disease and at every ten seconds a person dies from diabetes related causes in the world each year, over three million deaths world wide are tied directly to diabetes. The International Diabetes Federation estimates that the number of diabetic patients in India doubled from 19 million in 1995 to 40.9 million in 2007. It is projected to increase to 69.9 million by 2025 (Neogi, 2007).

In developing countries like India, diabetes occurs at a younger age affecting the most productive years of their lives than developed countries, where it generally occurs in individuals aged 65 and above. Therefore, India is expected to confront an enormous health care burden due to larger number of population suffering from this chronic disorder and its sequeale is attributed to changes in environmental factors, such as increased affluence which unmask a genetic or racial tendency for diabetes (Rao, 2004).

The use of anti-diabetic drug is a continuous process and patients have to take these drugs regularly. Results are encouraging if herbal drugs are taken along with dietary restrictions and exercise. One of the advantages of traditional medicinal plants is that these are available in plenty and have no side effects and are free from hypoglycemic reactions (Giri et al., 1987).

Recent studies on stevia produces evidence that the natural sweeteners stevioside and steviol, a product formed by enzymatic hydroxylation within the plant which is found in plant Stevia rebaudiana has been used for many years in the treatment of diabetes among Indians in Paraguay and Brazil. The stevioside and steviol, stimulate insulin secretion by direct action on beta cells and these compounds have potential role as anti hyperglycemic agent in the treatment of type 2 diabetes mellitus (Jeppesen et al., 2000).

Diabetes is closely linked to diet and nutrition, both with respect to its causation and management. Diabetes can be effectively managed and the risk of developing complications can be reduced substantially by changes in the diet, medication, physical activity and in some cases by insulin treatment. Diet control helps to reduce high blood sugar, to achieve ideal body weight and thereby reduce risk of complications (Tuomilehto et al., 2001). 
Manson (2002) reported that the management of diabetes mellitus not only requires the prescription by the physician but also intensive nutrition education and counseling of the patient. Diet plays a key role in the management of diabetes. General dietary guidelines for people with diabetes are not different from those of others, although the nutritional prescription must be individualized.

Considering the beneficial effects of stevia leaf powder on the nutritional health, the present study was under taken to study the effect of supplementation of stevia leaf powder on anthropometric parameters and gain in knowledge of the subjects.

\section{MATERIALS AND METHODS}

Selection of Subjects: Ninety NIDDM male subjects free from serious complications were selected from Punjab Agricultural University (PAU) Hospital, Ludhiana. The subjects selected were divided into three groups viz. Group I, Group II and Group III. Group I was given medicine prescribed by the doctor. Group II was given medicine and nutrition counselling and Group III was given medicine, nutrition counselling and stevia leaf powder.

Preparation of the Product: Stevia leaves were washed, dried and powdered and then filled in capsules of $500 \mathrm{mg}$ capacity.

Feeding of the Subjects: Two stevia leaf powder capsules every day, during breakfast and lunch were given to the subjects of Group III for a period of three months. Along with feeding, nutrition education was also given to Group II and III regarding diabetes, its management and importance of stevia in diabetes.

Nutrition education: Nutrition education was given to Group II and III subjects for a period of three months at an interval of fifteen days through individual and group contact with the subjects with the help of lectures-cum-demonstration method. Education relating to types, causes, complications, dietary management of diabetes and benefits of stevia was imparted to the patients.

Measurements of Anthropometric Parameters: Various anthropometric parameters viz. height, weight, mid upper arm circumference (MUAC), triceps skin fold thickness (TSFT), waist and hip circumference were measured. Body mass index (BMI) and waist to hip ratio (WHR) were calculated before and after the ex- perimental period according to method given by Jelliffe (1966)

Statistical Analysis: The data collected on food intake, nutrient intake, anthropometric parameters was analyzed statistically. The mean, standard error, paired-t value and CD value was calculated using computer programme package.

\section{RESULTS AND DISCUSSION}

Food Habits of the Subjects: The food habits of the subjects are shown in the Table 1. It was found that majority of the subjects in group I, II and III were vegetarians i.e. 70.0, 56.7 and $60.0 \%$ respectively. Whereas $30.0,43.3$ and $40.0 \%$ of the remaining subjects were non vegetarian. It was found that the majority of the subjects $60.0,63.3$ and $43.3 \%$ in group I, II and III respectively had a craving for sweet foods. The corresponding figures for the subjects in group I, II and III who liked salty food were 33.3, 23.3 and $46.7 \%$, fried foods were $60.0,70.0$ and $56.0 \%$ and fast foods were 23.3, 23.3 and $30.0 \%$ respectively.

Table 1: Food habits of the subjects

\begin{tabular}{lrrr}
\hline Pattern of diet & Group I & Group II & Group III \\
\hline a) Vegetarian or Non vegetarian & & \\
Vegetarian & $21(70.0)$ & $17(56.7)$ & $18(60.0)$ \\
Ova/NV & $9(30.0)$ & $13(43.3)$ & $12(40.0)$ \\
b) Food Likes and & Dislikes of the Subjects & Sweet food \\
Liked & $18(60.0)$ & $19(63.3)$ & $13(43.3)$ \\
$\quad$ Disliked & $12(40.0)$ & $11(36.7)$ & $17(56.7)$ \\
Salty food & & & \\
$\quad$ Liked & $10(33.3)$ & $7(23.3)$ & $14(46.7)$ \\
$\quad$ Disliked & $20(66.7)$ & $23(76.7)$ & $16(53.3)$ \\
Fried food & & & \\
$\quad$ Liked & $18(60.0)$ & $21(70.0)$ & $16(56.0)$ \\
$\quad$ Disliked & $12(40.0)$ & $9(30.0)$ & $14(46.0)$ \\
Fast food & & & \\
$\quad$ Liked & $7(23.3)$ & $7(23.3)$ & $9(30.0)$ \\
$\quad$ Disliked & $23(76.7)$ & $23(76.7)$ & $21(70.0)$ \\
\hline
\end{tabular}

Figures in parenthesis are percentage

Frequency of Food Consumption Pattern: The frequency of food consumption pattern of different food groups is presented in the Table 2,3 , and 4 . Initially, the frequency of cereal consumption by the subjects in group I, II and III was $100 \%$ thrice a day. Mainly cereals consumed were in the form of chappati followed by refined cereals in the form of bread, biscuits, samosas etc. No change was observed in cereal consumption after 3 months. The frequency of consuming pulses in group I, II and III was 83.3, 76.7 and 
$86.7 \%$ respectively once a day initially and after the study it was 83.3, 93.3 and $96.7 \%$ in group I, II and III respectively.

Before the study, 50.0, 60.0 and $80.0 \%$ of the subjects in group I, II and III used to consume GLV'S thrice a week. After three months, 50.0, 80.0 and $90.0 \%$ of the subjects in group I, II and III respectively consumed green leafy vegetables once in a week. The frequency of root and tuber consumption by the subjects was $73.3,90.0$ and $70.0 \%$ in Group I, II and III once in a day. Mainly tubers like potato were consumed by the subjects as vegetable or stuffed paronthas or as snack filling. After the study, the consumption pattern decreased to $70.0,43.3$ and $46.7 \%$ in group
I, II and III respectively once in a day. Initially, $40.0,56.7$ and $63.3 \%$ of the subjects in group I, II and III consumed fruits once in a day. Later on, after three months the percent figure for group I, II and III was 40.0, 83.3 and $83.3 \%$ respectively once in a day.

Before the study 70.0, 90.0 and $93.3 \%$ of the subjects in group I, II and III consumed milk and milk products respectively twice a day. Mainly milk consumed was in the form of tea, curd and drinking milk. After three months of study, the percent figure recorded for group I, II and III was $66.7,63.3$ and $60.0 \%$ respectively twice a day. Initially, before the study $26.7,30.0$ and $23.3 \%$ of the subjects in group I, II and III used to con-

Table 2: Frequency of consumption pattern of the subjects in group I

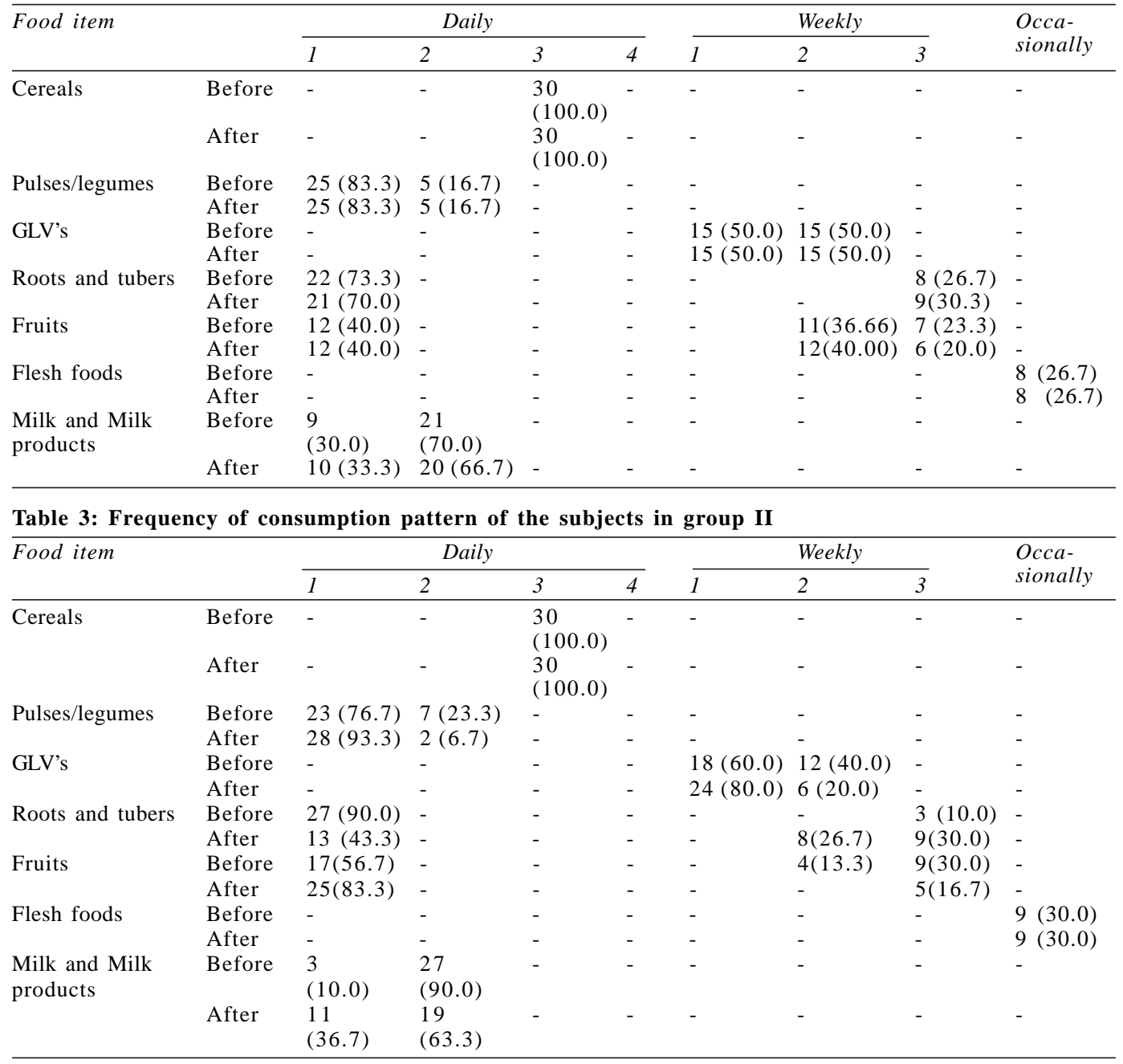


Table 4: Frequency of consumption pattern of the subjects in group III

\begin{tabular}{|c|c|c|c|c|c|c|c|c|c|}
\hline \multirow[t]{2}{*}{ Food item } & & \multicolumn{4}{|c|}{ Daily } & \multicolumn{3}{|c|}{ Weekly } & \multirow{2}{*}{$\begin{array}{l}\text { Occa- } \\
\text { sionally }\end{array}$} \\
\hline & & 1 & 2 & 3 & 4 & 1 & 2 & 3 & \\
\hline \multirow[t]{3}{*}{ Cereals } & Before & - & - & 30 & - & - & - & - & - \\
\hline & & & & $(100.0)$ & & & & & \\
\hline & After & - & - & $\begin{array}{l}30 \\
(100.0)\end{array}$ & - & - & - & - & - \\
\hline \multirow[t]{2}{*}{ Pulses/legumes } & Before & $26(86.7)$ & $4(13.3)$ & - & - & - & - & - & - \\
\hline & After & $29(96.7)$ & $1(3.3)$ & - & - & - & - & - & - \\
\hline \multirow[t]{2}{*}{ GLV's } & Before & - & - & - & - & $24(80.0)$ & $6(20.0)$ & - & - \\
\hline & After & - & - & - & - & $27(90.0)$ & $3(10.0)$ & - & - \\
\hline \multirow[t]{2}{*}{ Roots and tubers } & Before & $21(70.0)$ & - & - & - & - & $5(16.7)$ & $4(13.3)$ & - \\
\hline & After & $14(46.7)$ & - & - & - & - & $7(23.3)$ & $9(30.0)$ & - \\
\hline \multirow[t]{2}{*}{ Fruits } & Before & $19(63.3)$ & - & - & - & - & $2(6.7)$ & $9(30.0)$ & - \\
\hline & After & $25(83.3)$ & - & - & - & - & - & $5(16.7)$ & - \\
\hline \multirow[t]{2}{*}{ Flesh foods } & Before & - & - & - & - & - & - & - & $7(23.3)$ \\
\hline & After & - & - & - & - & - & - & - & $7(23.3)$ \\
\hline \multirow{2}{*}{$\begin{array}{l}\text { Milk and Milk } \\
\text { products }\end{array}$} & Before & $2(6.7)$ & $28(93.3)$ & - & - & - & - & - & - \\
\hline & After & $12(40.0)$ & $18(60.0)$ & - & - & - & - & - & - \\
\hline
\end{tabular}

sume flesh foods occasionally. The corresponding figures after three months were recorded to be the same.

Physical Activity: The physical activity pattern of the subjects is given in Table 5. It was observed that maximum number of the subjects i.e. $90.0,86.7$ and $86.7 \%$ in group I, II and III respectively lead a sedentary life. The subjects in group II and III were given counseling sessions. After three months 46.7 and $53.3 \%$ of the subjects in group II and III started to lead a moderate active life while there was no change in group I subjects. During each counseling session the subjects were firstly motivated to initiate the physical activity and then further increase time for their physical activity. Subjects were educated that how physical activity improves the physical fitness, increases energy expenditure, helps appetite regulation, favorably influences serum

Table 5: Physical activities pattern of the subjects before and after nutrition education and supplementation of stevia leaf powder

\begin{tabular}{llll}
\hline $\begin{array}{l}\text { Physical activity } \\
\text { pattern }\end{array}$ & Group & Before & After \\
\hline Sedentary & I & $27(90.0)$ & $27(90.0)$ \\
& II & $26(86.7)$ & $14(46.7)$ \\
Moderate & III & $26(86.7)$ & $16(53.3)$ \\
& I & $3(10.0)$ & $3(10.0)$ \\
Heavy & II & $4(13.3)$ & $16(53.3)$ \\
& III & $4(13.3)$ & $14(46.7)$ \\
& I & - & - \\
& II & - & - \\
& III & - & -
\end{tabular}

Figures in parenthesis are percentage lipoproteins, lowers blood pressure and importantly decreases the risk of coronary artery disease. Further, physical activity alters the interaction between insulin and its receptors and thus enhances insulin action, which helped to improve glycemic control and reduce the need for anti diabetic drugs.

Sleep Pattern of the Subjects: The sleep pattern is given in Table 6. Initially, 46.7, 40.0 and $33.3 \%$ of the subjects in group I, II and III respectively had sleeping hours of 7-8 hours. After the study, the corresponding percentage increased to 53.3, 60.0 and 66.7 per cent. Increase in sound sleep could be due to increase in their physical activity like morning and evening walk and light physical exercise taught to them during counselling sessions.

Table 6: Distribution of the subjects according to the sleep hours

\begin{tabular}{llll}
\hline Group & Sleep hours & Before & After \\
\hline I & $6-7$ & $16(53.3)$ & $14(46.7)$ \\
& $7-8$ & $14(46.7)$ & $16(53.3)$ \\
II & $6-7$ & $18(60.0)$ & $12(40.0)$ \\
& $7-8$ & $12(40.0)$ & $18(60.0)$ \\
III & $6-7$ & $20(66.7)$ & $10(33.3)$ \\
& $7-8$ & $10(33.3)$ & $20(66.7)$ \\
\hline
\end{tabular}

Figures in parenthesis are percentage

Anthropometric Profile of the Subjects: Anthropometric parameters of the subjects before and after supplementation of stevia leaf powder and nutrition counselling is given in Table 7 . The mean height of the subjects was 169.40 , 169.37 and $168.90 \mathrm{~cm}$ in Group I, II and III re- 
Table 7: Anthropometric parameters of the subjects (Mean \pm SE)

\begin{tabular}{|c|c|c|c|c|c|c|}
\hline Variables & & Group I & Group II & Group III & $C D$ & Suggested value \\
\hline Height(cm) & Before & $169.40 \pm 0.45$ & $169.37 \pm 0.33$ & $168.90 \pm 0.51$ & & \multirow{5}{*}{$60^{\#}$} \\
\hline \multirow[t]{4}{*}{ Weight (kg) } & Before & $79.63 \pm 0.72$ & $82.20 \pm 0.82$ & $79.00 \pm 0.86$ & $2.29 \%$ & \\
\hline & After & $78.53 \pm 0.70$ & $80.67 \pm 0.78$ & $76.27 \pm 0.86$ & $2.22 *$ & \\
\hline & $\%$ change & 1.4 & 1.9 & 3.5 & & \\
\hline & Paired t-value & 12.53 & $16.55^{\prime}$ & 18.08 & & \\
\hline \multirow[t]{4}{*}{ BMI $\left(\mathrm{kg} / \mathrm{m}^{2}\right)$} & Before & $27.73 \pm 0.31$ & $28.61 \pm 0.28$ & $27.55 \pm 0.37$ & NS & \multirow[t]{4}{*}{$20-25^{0}$} \\
\hline & After & $27.33 \pm 0.30$ & $28.08 \pm 0.27$ & $26.71 \pm 0.36$ & 0.902. & \\
\hline & $\%$ change & 1.4 & 1.9 & 3.0 & & \\
\hline & Paired t-value & $1.76^{\mathrm{NS}}$ & $5.45^{\circ}$ & 7.36 & & \\
\hline \multirow[t]{4}{*}{ MUAC $(\mathrm{cm})$} & Before & $29.06 \pm 0.26$ & $29.37 \pm 0.31$ & $29.07 \pm 0.28$ & NS & \multirow[t]{4}{*}{$32.2^{1}$} \\
\hline & After & $28.56 \pm 0.25$ & $27.80 \pm 0.31$ & $27.22 \pm 0.30$ & 0.829 & \\
\hline & $\%$ change & 1.7 & 5.3 & 6.4 & & \\
\hline & Paired t-value & 3.24 & 8.52 & 9.35 & & \\
\hline \multirow[t]{4}{*}{ TSFT (cm) } & Before & $11.38 \pm 0.16$ & $12.37 \pm 0.07$ & $12.24 \pm 0.13$ & 0.364 & \multirow[t]{4}{*}{$12.2^{2}$} \\
\hline & After & $11.28 \pm 0.15$ & $12.05 \pm 0.07$ & $11.76 \pm 0.14$ & $0.377^{*}$ & \\
\hline & $\%$ change & 0.9 & 2.6 & 3.9 & & \\
\hline & paired t-value & $2.00^{\mathrm{NS}}$ & 4.08 & 10.26 & & \\
\hline \multirow[t]{4}{*}{ WHR } & Before & $0.96 \pm 0.00$ & $0.97 \pm 0.01$ & $0.95 \pm 0.01$ & & \multirow[t]{4}{*}{$1.0^{3}$} \\
\hline & After & $0.95 \pm 0.00$ & $0.94 \pm 0.00$ & $0.91 \pm 0.00$ & $0.020^{\circ}$ & \\
\hline & $\%$ change & 1.0 & 3.1 & 4.2 & & \\
\hline & Paired t-value & 3.54 & $4.96^{\circ}$ & $4.91^{\circ}$ & & \\
\hline
\end{tabular}

Significant at $1 \%$ Significant at $5 \%$

NS - Non significant

\# ICMR (2003)

0 Garrow (1981)

1 NCHS Standard

2 Jelliffe (1966)

3 Ghafoorunissa (1994)

spectively. The initial mean weight recorded was $79.63,82.20$ and $79.00 \mathrm{~kg}$ in Group I, II and III respectively. After three months there was a significant decrease $(\mathrm{p} \leq 0.01)$ in Group II and III i.e. 80.67 and $76.27 \mathrm{~kg}$, respectively and a non significant reduction $(\mathrm{p} \leq 0.01)$ in group I i.e. 78.53 $\mathrm{kg}$. The decrease in weight in Group II and III could be due to the nutrition education given to the subjects. It was observed that there was a significant decrease $(\mathrm{p} \leq 0.01)$ in the body mass index (BMI) values in group II and III after three months. Initial mean body mass index (BMI) recorded was 27.73, 28.61 and 27.55 in Group I, II and III respectively and the corresponding values after three months were 27.33, 28.08 and 26.71. There was 1.4, 1.9 and $3.0 \%$ decrease in BMI after three months in group I, II and III respectively. The initial mean mid upper arm circumference (MUAC) in group I, II and III recorded was $29.06,29.37$ and $29.07 \mathrm{~cm}$ respectively. After three months, the corresponding figures recorded were as $28.56,27.80$ and $27.22 \mathrm{~cm}$. There was a significant reduction $(\mathrm{p} \leq 0.01)$ in Group I, II and III. Initial mean triceps skin fold thickness values recorded was $11.38,12.37$ and $12.24 \mathrm{~cm}$ which decreased to $11.28,12.05$ and $11.76 \mathrm{~cm}$ after three months in Group I, II and III respectively. There was a statistically significant decrease $(\mathrm{p} \leq 0.01)$ in triceps skin fold thickness (TSFT) values of the subjects in Group III subjects after three months. However, there was a non significant decrease $(\mathrm{p} \leq 0.01)$ in triceps skin fold thickness values in Group I and II after three months. In comparison with the standard value $(16.5 \mathrm{~cm})$ laid down by Jelliffe (1966) of adult males the values were lower in all the three groups. The mean values of waist hip ratio (WHR) before any intervention was $0.96,0.97$ and 0.95 in group I, II and III respectively. A significant decrease $(\mathrm{p} \leq 0.01)$ was seen after three months in waist hip ratio in Group I, II and III after three months. After three months the values recorded were $0.95,0.94$ and 0.91 respectively. The waist hip ratio (WHR) in all the three groups lies in between the standard value of $0.8-1 \%$ as given by Ghafoorunissa (1994).

Distribution of Subjects According to the BMI: Distribution of the subjects according to the BMI are presented in Table 8. It was seen that maximum number of the subjects lied in the BMI range 25-30 and above 30 before the study. But after three months, the number of subjects 
Table 8: Distribution of subjects according to their BMI before and after nutrition education and supplementation of stevia leaf powder

\begin{tabular}{llll}
\hline BMI $\left(\mathrm{kg} / \mathrm{m}^{2}\right)^{+}$ & Group I & Group II & Group III \\
\hline $20-25$ & & & \\
$\begin{array}{l}\text { Before } \\
\text { After }\end{array}$ & $1(3.3)$ & $0(0.0)$ & $3(10.0)$ \\
$25-30$ & $1(3.3)$ & $0(0.0)$ & $4(13.3)$ \\
Before & $25(83.3)$ & $24(80.0)$ & $22(73.3)$ \\
After & $25(83.3)$ & $26(86.7)$ & $23(76.7)$ \\
$>30$ & $4(13.3)$ & $6(20.0)$ & $5(16.7)$ \\
Before & $4(13.3)$ & $4(13.3)$ & $3(10.0)$ \\
After &
\end{tabular}

Figures in parenthesis are percentage

+ James et al (1988)

decreased in the BMI range of above 30 and increased in 25-30 BMI range in Group II and III.

Gain in Knowledge: The knowledge gain of the subjects is shown in the Table 9. Nutrition counseling was imparted to the subjects of Group II and III by individual and group contacts in the form of nutrition lectures and demonstrations etc. for a period of three months. The subjects of Group I were not imparted any nutrition counseling during these three months. The evaluation of the scores was done before (pre test) and after three months (post test) of intervention to assess the diabetes and stevia knowledge of the subjects in all the three groups. The average gain in knowledge is presented in the Table 9.

It was seen that there was a significant increase $(\mathrm{P} \leq 0.01)$ in knowledge, attitude, practices and hence total knowledge of the subjects in
Group II and III after three months of the study while there was a non significant increase $(\mathrm{P} \leq 0.01)$ in the subjects of Group I. The increase in KAP scores of the subjects in Group II and III could be due to the effect of nutrition counselling given to the subjects like increase in consumption of whole cereals, sprouted pulses, green leafy vegetables, salads, fruits etc. They were also told to do moderate exercise.

\section{CONCLUSION}

It can be inferred from the results that supplementation of stevia leaf powder along with nutrition counselling improved the anthropometric parameters of the subjects. Nutrition counselling improved the knowledge, attitude and practices score of the subjects.

\section{RECOMMENDATIONS}

Nutrition counselling by the dietician plays an important role in the management of diabetes. There is a need to conduct well designed community based diabetes prevention programme to stem the rising trends of diabetes in the country.

\section{REFERENCES}

Ghafoorrunissa, Krishnaswamy, M. 1994. Diet and Heart Disease. Hyderabad: National Institute Of Nutrition.

Giri. J., Suganthi, B. and Neera, G. 1987. "Effect of Tulsi (Ocimuns sanctum) on diabetes mellitus". Ind. J. Nutr. Dietet., 24: 337-41.

Table 9: KAP Scores obtained by the subjects

\begin{tabular}{|c|c|c|c|c|c|}
\hline & & Group I & Group II & Group III & $C D$ \\
\hline \multirow[t]{4}{*}{ Knowledge } & Before & $13.00 \pm 0.13$ & $15.17 \pm 2.01$ & $14.03 \pm 2.41$ & $2.13^{\prime \prime}$ \\
\hline & After & $13.11 \pm 0.18$ & $42.11 \pm 1.91$ & $44.11 \pm 3.11$ & 6.1321 \\
\hline & $\%$ gain & 0.8 & 177.6 & 214.4 & \\
\hline & Paired t-value & $0.71^{\mathrm{NS}}$ & 18.18 & 20.18 & \\
\hline \multirow[t]{4}{*}{ Attitude } & Before & $4.07 \pm 1.13$ & $3.03 \pm 1.84$ & $2.11 \pm 1.18$ & $1.91^{*}$ \\
\hline & After & $4.18 \pm 1.11$ & $8.49 \pm 1.16$ & $9.39 \pm 12.01$ & 11.318 \\
\hline & $\%$ gain & 2.7 & 180.2 & 345.0 & \\
\hline & Paired t-value & $0.89^{\mathrm{NS}}$ & 25.89 & 27.39 & \\
\hline \multirow[t]{4}{*}{ Practices } & Before & $3.33 \pm 1.08$ & $4.13 \pm 0.13$ & $3.21 \pm 1.31$ & NS \\
\hline & After & $3.48 \pm 1.31$ & $9.01 \pm 0.89$ & $8.11 \pm 4.33$ & $4.318^{\circ}$ \\
\hline & $\%$ gain & 4.5 & 188.2 & 152.6 & \\
\hline & Paired t-value & 3.11 & 30.88 & 33.33 & \\
\hline \multirow{4}{*}{ Total knowledge } & Before & $20.41 \pm 1.11$ & $22.33 \pm 0.69$ & $19.35 \pm 3.42$ & 3.112. \\
\hline & After & $20.77 \pm 0.79$ & $59.61 \pm 0.66$ & $61.61 \pm 0.59$ & 9.733. \\
\hline & $\%$ gain & 1.8 & 167.0 & 218.3 & \\
\hline & Paired t-value & $2.13^{\mathrm{NS}}$ & 19.39 & 20.18 & \\
\hline
\end{tabular}

Significant at $1 \%$

"Significant at 5\%

NS - Non significant 
ICMR. 2003. Dietary Guidelines for Indians. A Manual. Hyderabad: National Institute of Nutrition.

James, W.P.T., Ferro-Lzzi and J.C. Waterlow. 1988. "Definition of chronic energy deficiency in adults. Report of a working party of International Dietary Energy Consultative Group". European J. Clin. Nutr., 42: 961-81.

Jelliffe, O.B. 1966. The Assessment of Nutritional Status of Community. Geneva: World Health Organization.

Jeppensen, P.B., S. Gregerson, C.R. Poulsen and K. Hermansen. 2000. "Stevioside acts directly on pancreatic beta cells to secrete Insulin." Metabolism, 49: $208-14$

Manson, P. 2002. "Cardiovascular diseases in type 2 diabetes mellitus." Archives of Internal Medicine, 163: $33-40$

NCHS. 1987. "Anthropometrics reference data and prevlence of overweight, US 1766-80". Vital and Health Statistics, Series 11, No. 238.

Neogi, S. 2007. "India, world diabetes capital." Hindustan Times, Sept 3, 2007.

Rao, K.M. and S. Kumar 2004. "Diabetes ongoing research". The Hindu Business Time, www. sagardiabeticcentre. com.

Tuomilehto, J., J. Lindstrom and J.G. Eriksson, 2001. "Prevention of type 2 diabetes mellitus by changes in life style among subjects with impaired glucose tolerance." N. Eng. J. Med., 344: 1343-1350. 